www.nature.com/jes

\title{
EDITORIAL
}

\section{In memory of Michael D. Lebowitz, Ph.D.}

Journal of Exposure Science and Environmental Epidemiology (2014) 24, 1-2; doi:10.1038/jes.2013.49

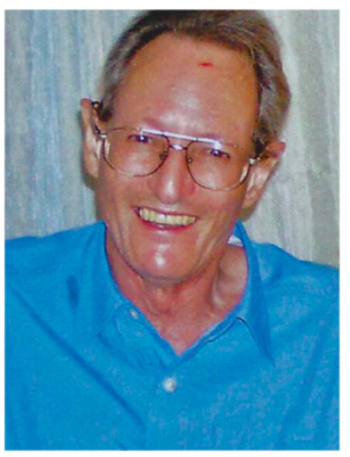

Michael David Lebowitz, Ph.D., died quietly at home on 29 April 2013. Michael was a pioneer of exposure science; he uncovered relationships between respiratory disease, environmental exposures and host susceptibility whether intrinsic or self-induced. He used methodologies common to epidemiology, environmental sciences, medicine and biostatistics. Michael marshaled precise, accurate, cost-effective and timely field/clinic-based measurements to evaluate incremental changes in health status through time. Michael used this approach in numerous studies throughout his life. The Tucson Epidemiologic Study of Airway Obstructive Disease (TESAOD), a continuously funded 25-year NIH Specialized Center of Research (SCOR) study, was designed by Mike and launched his research career in pulmonary medicine. His career in exposure science was capped as the Principle Investigator of the National Human Exposure Assessment Survey (NHEXAS) in Arizona. NHEXAS evaluated multiple pollutants in multiple media through multiple routes and pathways through the auspices of the Environmental Protection Agency. The work measured the complex pollutant encounters people experience in daily life and related them to body burden as reflected by biomarkers.

Michael D. Lebowitz was born in Brooklyn, NY, to Rachel Dick and Harry Lebowitz on 21 December 1939. Mike spoke of living in the city surrounded by family members and friends, who spoke an array of languages and came from multiple cultures, each with its own ethnic food and political ideology. Mike described intense intellectual discussion about issues of the day. Rachel was a liberal political activist throughout her life, and provided Michael with the opportunity to think about social justice issues. These influences were later reflected in his public health work and environmental justice concerns. Times were tough in the late 1940s and Mike described early recycling/salvage operations he participated in with his father and uncle. 'People throw away things that are really useful...what a waste! That is perfectly good.' Mike never wanted anything to go to waste and was a natural daily practitioner of the $3 R^{\prime} s$ of the green movement - reduce, reuse, recycle. His curiosity and early life experiences were reflected in his academic pursuits and provided great first-hand knowledge for the epidemiologist and exposure scientist he later became. At the age of 14 years, Michael moved from the polyglot intensity and bustle of New York across country to the San Fernando Valley in the greater Los Angeles area.

Mike Lebowitz and Joyce Schmidt were married in 1960 and for 52 years enjoyed a life of travel, photography, gourmet cooking, music, and contemplative reading and child-rearing together. They have three children (Jon Lebowitz, Kira Lebowitz (Olds) and Debra Darby) and four grandchildren (Robert Payne, Siobhan and Liam Darby and Bayley Olds). Mike completed an undergraduate degree in psychology at the University of California at Berkeley in 1961 and a master degree in biostatistics in 1965. During this time, Mike was employed at the Alameda County Health Department. Following graduation with his MS from Berkeley, Mike worked at the California Health Department as a biostatistician. In 1967, Mike and his family moved to Seattle where he started a Ph.D. in Biostatistics (with Donovan Thompson). Although he had done some limited sailing when in California, Mike signed up for sailing classes and spent considerable time on Puget Sound with a friend who owned a sail boat.

At the University of Washington, Michael started working with Jim McCarroll, an environmental scientist who became his mentor. He undertook a project examining the association between daily mortality, air pollution and weather. The multidisciplinary dissertation earned him his Ph.D. in Epidemiology and International Health in 1971 and required four department chairs to serve on his graduate committee (Environmental Sciences, Epidemiology and International Health, Biostatistics and Sociology). The complexity of this project paved the way for his move to Tucson, where he joined the pulmonary group at the new College of Medicine at the University of Arizona in 1971.

When the early SCOR investigators initiated the TESAOD survey, they collected baseline information by questionnaire, obtained an initial spirometry measure and evaluated participants for skin test reactivity to common allergens. Using the tools of the day, the team was able to look at lung function changes in a wellcharacterized population and examine continued lung function change through time. The questionnaire characterized disease states and behaviors, particularly smoking, which over the 25-year span of the study demonstrated the long-term impact of smoking on lung function and its role in COPD. These data, examined by the team, indicated that lung function declines more rapidly among smokers, but when smoking stops, lung function returns to the same rate of normal loss as experienced by those who never smoked. People do not regain lung function when they stop smoking, but the rate of lung function loss slows to normal.

During 1978-79, Michael was a visiting fellow at the University of London's postgraduate cardiothoracic institute at the Brompton Hospital. Michael loved working in the clinic and examining cases that manifest the symptoms and diseases he had studied. The practical application provided him with greater confidence pursuing the root causes of asthma, COPD and other respiratory diseases. He also fell in love with London, its customs and people. Following the year in London, he was an inveterate consumer of tea and dark beer with a penchant for fedoras, scarves and rain slickers.

Michael and other researchers at the UA College of Medicine initiated the formation of the Graduate Interdisciplinary Program in Epidemiology. Michael was the stalwart leader who nurtured the program through its early development and brought the program to the newly forming College of Public Health. Since its inception, the epidemiology program at the University of Arizona has graduated 42 MS and 40 Ph.Ds. Michael always challenged his students and once they got to know him, they loved him. They enjoyed his quirky, subtle sense of humor. He gave his time unstintingly and nurtured many through early 
career development. Michael loved seeing other people (of any age) learn new things and launch on their own path.

Michael had an interest in pollen exposures and wanted to relate them to human health. Mary Kay was investigating issues of pollen production variability in response to weather variables and real-time dispersal of these microscopic organic particles. During their first meeting Mike listened and they immediately ordered Burkard traps and scouted-out sampler locations. Later, Mike became the minor chair of Mary Kay's PhD Committee and a long collaboration ensued addressing the impact of environmental exposures on human health. During the late 1970s they began looking at indoor residential and local outdoor pollutants in the TESAOD population. The team, under Michael's leadership, explored the impact of criteria pollutants, weather, naturally occurring and anthropogenic environmental contaminants and their confounders on variability in human peak flow. In recent years, Michael has been known for his work with NHEXAS Arizona and related studies as described above.

Demetrios met Mike in 1979 when they served in the National Academy of Sciences Committee on Indoor Air Pollutants. Later on they were members of a series of WHO committees on Indoor Pollution and co-wrote the NHEXAS proposal, along with Mary Kay and Sydney Gordon. Mike and Demetrios developed a close friendship and they and their spouses traveled all over the world. Mike taught Demetrios to enjoy hiking, but he failed to convince him that cooking could be a desirable and entertaining activity. Although Demetrios induced Mike to enjoy single malt scotch, he failed to convince him that an old historical building and its famous inhabitants were worth spending time to explore. Mike and Joyce love birding and Demetrios and Carol learned about birds in Greece, Britain, Canada, Finland, Scotland, Germany, Alaska, Arizona, Utah, Michigan and Illinois.
Mike encouraged others to step-up. Nowhere was this more apparent than in his service to science. He was a fellow of the American College of Chest Physicians, the American College of Epidemiology and the Collegium Ramazzini. He was elected to Delta Omega and the International Academy of Indoor Air Sciences. He was a member of many other groups and was endlessly reviewing articles, grants and documents all for the advancement of science. He built and chaired the Division of Epidemiology and Biostatistics at the University of Arizona and was a founding member of the Mel and Enid Zuckerman College of Public Health. The International Society of Exposure (Assessment) Science received a great deal of his attention. Michael was a founding member of the Society, a Conference chair, Past President and the recipient of the Society's greatest honor: the Wesolowski Award. Mike was a renaissance man, a scholar, an educator, a photographer, a classical music devotee, a sports expert, a chef and food connoisseur, a hiker, a bird spotter and a great friend. We will all miss him and mourn his loss.

\section{CONFLICT OF INTEREST}

The authors declare no conflict of interest.

Mary Kay O'Rourke ${ }^{1}$ and Demetrios J. Moschandreas ${ }^{2}$ ${ }^{1}$ The University of Arizona, Community, Environment and Policy, 1295 North Martin Avenue, PO Box 245210, Tucson, Arizona 85724, USA and

2 Illinois Institute of Technology, Civil, Architectural and Environmental Engineering, 3201 South Dearborn Street, Chicago, Illinois 60201, USA E-mail: MKOR@email.arizona.edu or moschandreas@iit.edu 